\title{
Performance Comparison of Different Controllers for Flow Process
}

\author{
B.Pradeepa \\ Department of ICE, \\ Saranathan college of \\ Engineering, \\ Venkateswara Nagar, \\ Panjappur, \\ Trichy. \\ H. Kala \\ Assistant Professor, \\ Saranathan college of \\ Engineering, \\ Venkateswara Nagar, \\ Panjappur, \\ Trichy.
}

\author{
R.Kiruthiga \\ Department of ICE, \\ Saranathan college of \\ Engineering, \\ Venkateswara Nagar, \\ Panjappur, \\ Trichy.
}

\author{
S.Abirami \\ Assistant Professor, \\ Saranathan college of \\ Engineering, \\ Venkateswara Nagar, \\ Panjappur, \\ Trichy.
}

\author{
P.B.Nevetha \\ Department of ICE, \\ Saranathan college of \\ Engineering, \\ Venkateswara Nagar, \\ Panjappur, \\ Trichy.
}

P.Sujithra
Department of ICE,
Saranathan college of
Engineering,
Venkateswara Nagar,
Panjappur,
Trichy

\begin{abstract}
This paper deals with the improvement of diverse control techniques for flow control process. The different controllers are Proportional Integral Derivative controller (PID), Model Predictive Controller (MPC) and Internal Model Controller (IMC) which are computer-generated in Matlab environment. The three parameters of PID controller ought to be tuned to the process to achieve a reasonable closed loop process performance. Here the performance study of the conventional PID controller,Internal model controller and model predictive controller has been bring into play of Matlab and Simulink. The evaluation of various time domain parameters is done to establish that the Model predictive controller has petite overshoot and rapid response as compared to PID controller and IMC based PID controller. The performance evaluation demonstrates a good relationship between PID,MPC and IMC controller.
\end{abstract}

\section{Keywords}

PID controller, IMC controller, MPC controller, tuning methods, matlab.

\section{INTRODUCTION}

In several industrial plants, measuring the flow of liquids is an essential and obligatory thing. In recent years, flow control has turn into a highly multi-disciplinary research activity encircling theoretical, computational and experimental fluid dynamics[2]. In recent years ,many new types of controllers have been introduced. PID and MPC are two control algorithms extensively used in industrial applications [6]. Even though, a PID controller has only three adjustable parameters, finding apposite settings is not easy, consequential in many controllers being inadequately tuned and time excruciating plant tests often being requisite to achieve process parameters for improved and explain the best result among controller settings[5]. There are quite a lot of approaches for controller tuning, where ZN-PID,TL,C-H-R and IMC-PID tuning methods are so admired. The problems of PID are overcomed by the most sophisticated controller named as model predictive controller[1]. In this section we are going to evaluate the concert of various controller which are mentioned above them.

The schematic diagram for flow process is shown as:

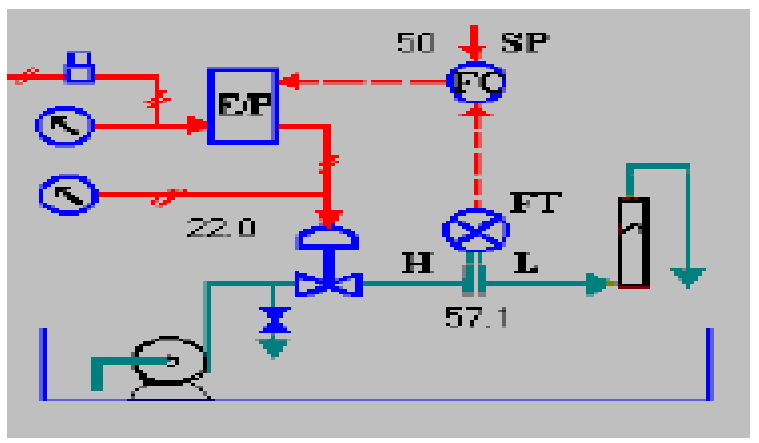

Process indentification:

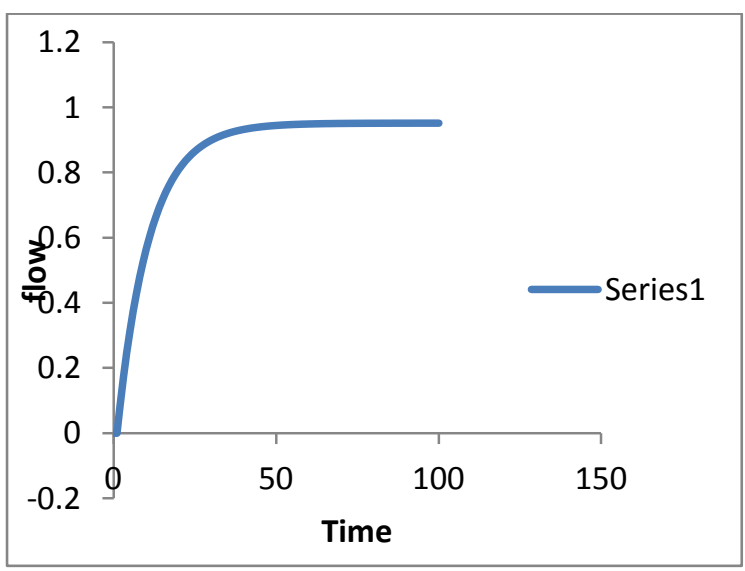

This process is recognized as the FODT flow process. 
The transfer function for such a system by a specified by a equation

$$
G_{p}(s)=\frac{\mathrm{Ke}^{-\theta s}}{(\tau s+1)}
$$

$\Rightarrow$ From the process reaction curve the transfer function was obtained.

$\Rightarrow$ Transfer function for this existing flow process is:

$$
G p(s)=\frac{0.952 e^{-s}}{10 s+1}
$$

\section{PID CONTROLLER}

PID control is effortless in principle, uncomplicated to tune ,robustness and booming realistic application, which is still extensively used in industrial process control. The PID controller is an primary minuscule proportion of the control loop in the process industry[4] .Even though many advanced control modus operandi are based on a PID control algorithm, the conservative PID control algorithm cannot realize ideal manage effect in any pragmatic production process with nonlinear and time varying uncertainty[3]. Advanced control methods can exemplify significantly improved performance but PID control technique can be adequate for many industrial control loops.

\subsection{Controller Design}

Many methods are there to propose a perfect PID such as Ziegler Nichols(ZN)tuning method, cohen-coon and Internal model controller. Here the parameters of PID are resolute and tuned so as to attain a accurate steady state response for a step input[8]. Tuning rules work quite well when you have a analog controller, a system that is linear, monotonic and slothful and response that is subjugated by a single pole exponential delay.

\begin{tabular}{|c|c|c|c|}
\hline $\begin{array}{l}\text { CONTROLLE } \\
\mathrm{R}\end{array}$ & $\mathrm{k}_{\mathrm{c}}$ & $\tau_{\text {int }}$ & $\tau_{\text {der }}$ \\
\hline $\mathrm{P}$ & $\frac{K U}{2}$ & & \\
\hline $\mathrm{PI}$ & $\frac{K U}{2.2}$ & $\frac{P U}{1.2}$ & \\
\hline PID & $\frac{K U}{1.7}$ & $\frac{P U}{2}$ & $\frac{P U}{8}$ \\
\hline
\end{tabular}

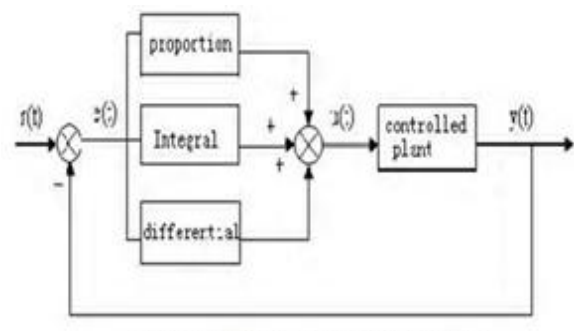

Figure 1: The analog PID Controller

\section{2 $\mathrm{ZN}$ tuning}

$\mathrm{ZN}$ tuning rule is a base for a forth coming new generation of PID technology." superior performance and easy to use". It is a algorithmic PID tuning rule that generate excellent PID gain parameters such as controller path gain( $\mathrm{Kp}$ ), controllers integral time constant (Ti), the controllers derivative time constant(Td)[4]. Here two calculated feedback loop parameters derived from measurements such as the period $\mathrm{Pu}$ of the oscillation frequency at the stability limit and gain margin $\mathrm{Ku}$ for loop stability[8]. From the bode plot, frequency is renowned at $180^{\circ}$. In nyquist diagram the gain $\mathrm{k}_{\mathrm{u}}$ was indomitable with the aid of frequency value.With the ku value, pu was intended from the equation [3]:

$$
\mathrm{P}_{\mathrm{u}}=\frac{2 \pi}{\mathrm{Wc}_{0}}
$$

Thus from this two values $\mathrm{ku}$ and $\mathrm{pu}$,parameters like proportional gain, integral time and derivative time constant was established by Ziegler Nichols table and substituted in the PID controller block.

Ziegler Nichols tuning table based on ultimate gain(ku)and ultimate period $(\mathrm{pu})$.

The resulted graph is shown below:

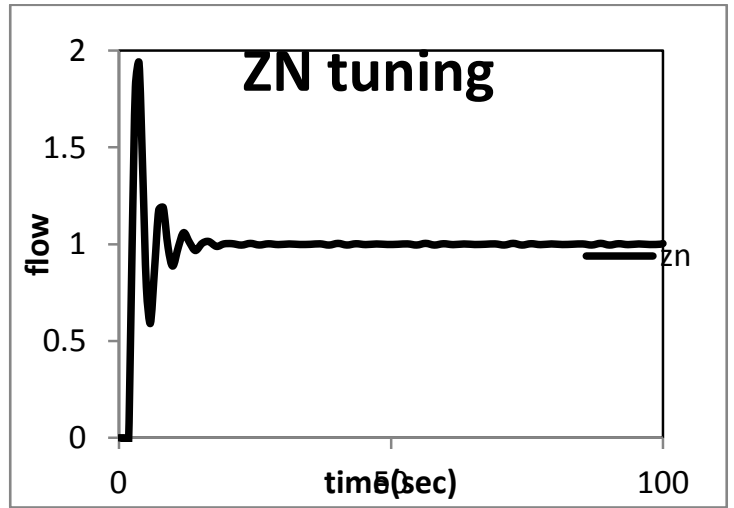

\section{COHEN-COON TUNING METHOD}

Cohen-coon system of controller tuning corrects the sluggish, steady state response given by the Ziegler Nichols method when there is a large dead time(process delay)qualified to the open loop time constant, a large process delay is essential to make this method practical because or else unduly large controller gains will be predicted.

This method is only appropriate for first order models with time delay,due to the reality that the controller does not immediately respond to the disturbance. 
This method is classified as an "offline"method of tuning, sense that a step change can be introduced to the input once it is at stable[4]. Then the output can be calculated depends upon the time constant and the time delay and this response can be used to evaluate the initial control parameters.

\section{cohen-coon tuning table}

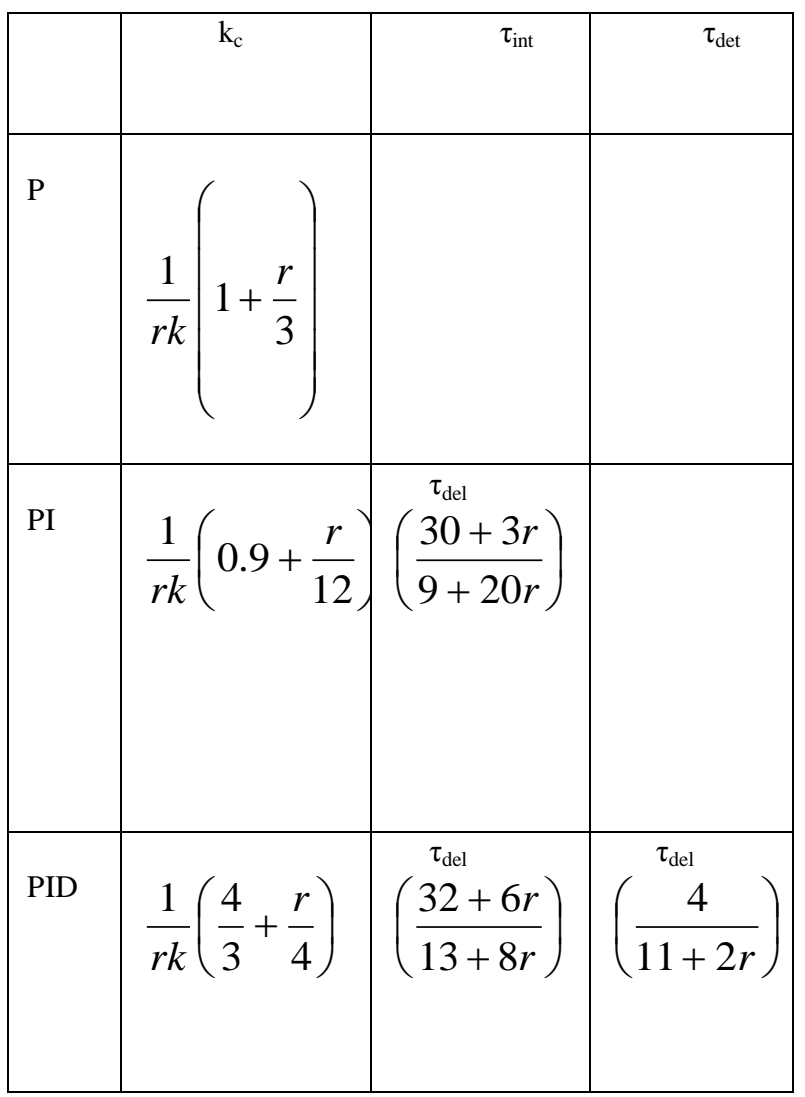

From this table the value of special parameters like proportional gain,integral time and derivative time constant and this values are given in PID controller .

This type of tuning is known as cohen-coon tuning method. Its consequent graph is shown below:

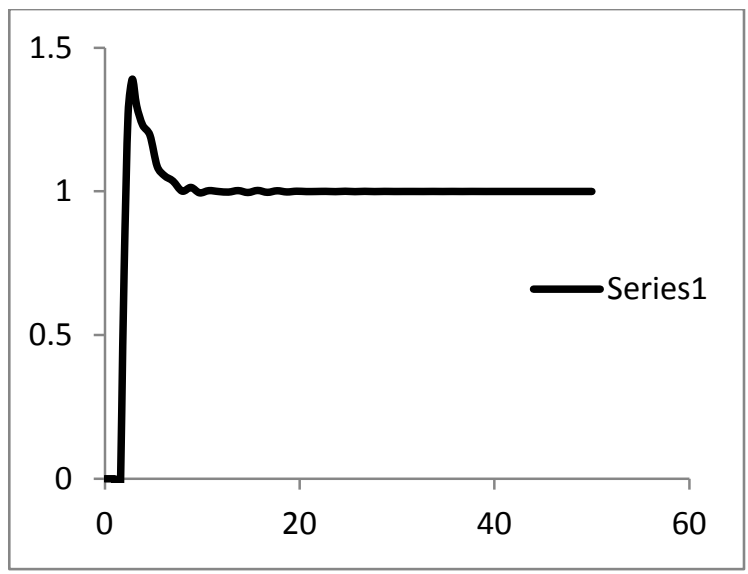

\subsection{Tyreus - Luyben Method}

The Tyreus- Luyben tuning method is fairly like to be same as the Ziegler-Nichols method but the final controller settings are diverse. Also this method only allows settings for PI and PID controllers. These settings that are based on ultimate gain and period Like Z-N method this method is time taking one and makes the system to margin if unstability. Many other algorithms have been proposed by obtaining decisive data (ultimate gain and frequency) under more adequate conditions.

\begin{tabular}{l} 
The tuning \\
\hline
\end{tabular}

and the respected TL graph is shown.

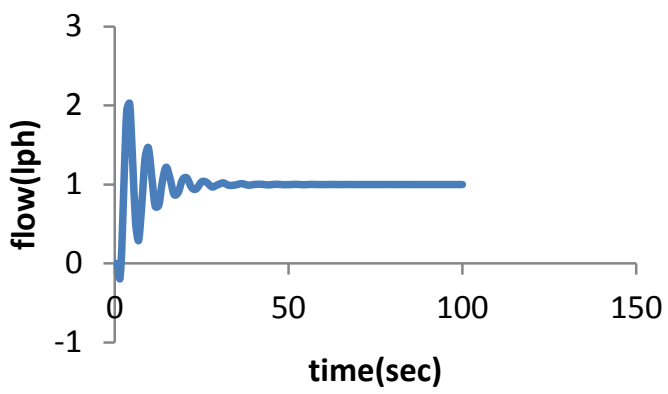

\subsection{C-H-R METHOD}

This method was projected by Chien, Hrones and Reswich it is a modification of open loop Ziegler and Nichols method[11]. They proposed to exploit "quickest response without overshoot" or "quickest response with $20 \%$ overshoot" as design decisive factor. It made a important study that tuning for set point responses and load disturbance responses are dissimilar. To tune the controller according to the $\mathrm{CH}-\mathrm{R}$ method the parameters of first order plus dead time model are dogged in the same basis of the $\mathrm{Z}-\mathrm{N}$ method. when the $0 \%$ overshoot criteria is used, the gain and the derivative time are lesser and the integral time is larger[11]. This means that the proportional action and the integral action, as well as the derivative action, are smaller.

The tuning formula of proposed technique is,

\begin{tabular}{cccc}
\hline Controller & $\mathrm{k}_{\mathrm{c}}$ & $\tau_{\mathrm{I}}$ & $\tau_{\mathrm{D}}$ \\
\hline $\mathrm{P}$ & $\frac{1}{K_{m}} \cdot \frac{\tau_{m}}{d}$ & - & - \\
$\mathrm{PI}$ & $\frac{0.9}{K m} \cdot \frac{\tau_{m}}{d}$ & $\frac{\mathrm{d}}{0.3}$ & - \\
$\mathrm{PID}$ & $\frac{1.2}{K m} \cdot \frac{\tau_{p n}}{d}$ & $2 \mathrm{~d}$ & $0.5 \mathrm{~d}$ \\
\hline
\end{tabular}

The resulted CHR graph is presented below:- 


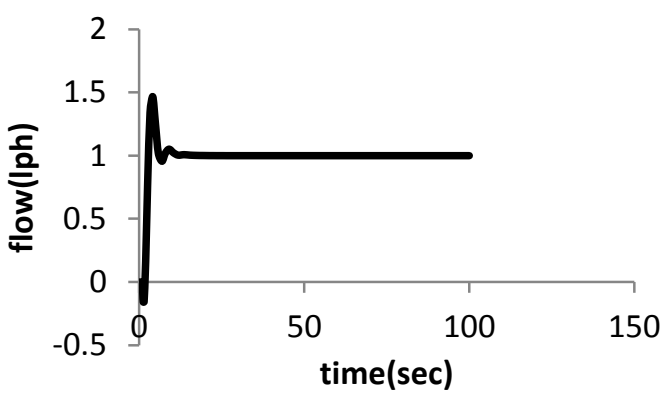

\section{IMC BASED PID CONTROLLER}

Internal Model Control (IMC) is a recurrently used technique that gives a apparent mode for the devise and tuning of a range of types of control. The ability of proportional-integral (PI) and proportional-integralderivative (PID) controllers to congregate most of the control objectives has led to their extensive acceptance in the control industry[3]. The Internal Model Control (IMC)vcbased approach for controller design is one of them using IMC and its equivalent IMC based PID to be used in control applications in industries[4]. It is for the reason that, for an authentic process in industries PID controller algorithm is simple and robust to handle the model inaccuracies and hence using IMC-PID tuning method a obvious trade-off between closed-loop presentation and robustness to model inaccuracies is achieved with a particular tuning parameter

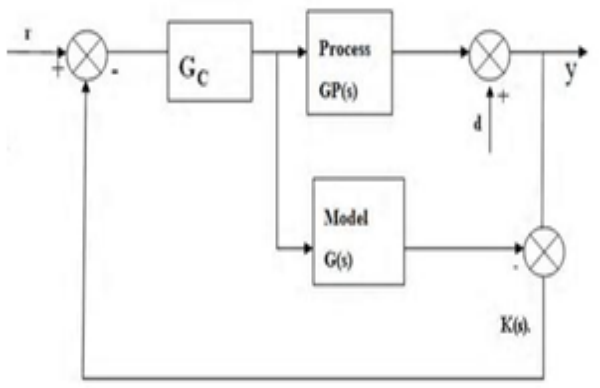

The IMC structure can be rearranged to form a typical feedback control system that can effortlessly hold open loop unstable system as not the case with IMC. This modification of the IMC design procedure is developed to get better the input disturbance rejection[3]. The IMC based PID structure which uses a standard feedback formation uses the process model in a secret manner i.e. PID tuning constraints are regularly attuned based on the transfer function form but it is not always lucid how the process model affects the tuning result. In the IMC controller Qc(s) is truely based on the superior part of the process[5] . Also the IMC usually results in only one tuning parameter, the close loop time constant (filter tuning factor). The IMC based PID tuning parameters are then the function of this $\tau$ (time constant). The selection of the closed loop time constant is directly correlated to the robustness (sensitivity to the modular of the closed loop system)[1]. Also, for open loop unstable processes it is obligatory to implement the IMC tactic in standard feedback form, because the IMC suffers from internal stability troubles. even if the IMC based PID controller will not give the same performance when there are process time lags because the IMC based PID actions uses an estimate for the dead time[2]. If the process has no time delays and the inputs do not strike a constraint then the IMC based PID controller give the same performance as does the IMC.

\subsection{Tuning formulas for IMC}

\begin{tabular}{|c|l|l|}
\hline Kp & \multicolumn{1}{|c|}{$\mathrm{Ti}$} & $\mathrm{Td}$ \\
\hline$\frac{1}{K}\left(\frac{2 \tau / \theta+1}{2 \tau c / \theta+1}\right)$ & $\theta / 2+\tau$ & $\frac{\tau}{2\left(\frac{\tau}{\theta}\right)+1}$ \\
\hline
\end{tabular}

The response of the IMC based PID controller is shown below:

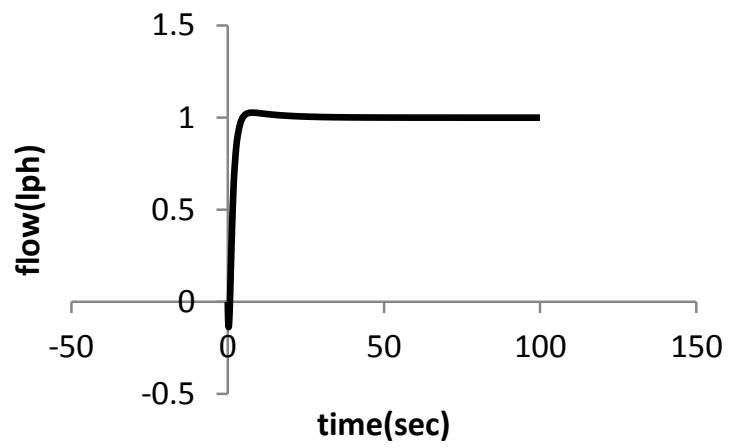

\section{MODEL PREDICTIVE CONTROLLER}

It is the most sophisticated form of advanced process control. It is a model based approach. Model predictive controllers rely on lively models of the structure, a linear practical models obtained by system identification [7].simple systems with dynamic uniqueness that are difficult for PID controllers include large time delays and high-order dynamic can very well be handled with MPC .it handle difficult to control tribulations such as time delay, non minimum phase ,non linearity, open loop instability, constraints and combination thereof[6]. Also ,it will handle relations of a multivariable nature. Second ,despite its complexity, implementation of MPC is fairly straight forward because there are good quality robust packages available[6].Most uses the current plant measurement ,the current dynamic state, the MPC models, and the process variable targets and limits to calculate future changes in variables[7]. These changes are calculated to hold the reliant variable. The MPC classically sends out only the first change in each independent variable to be employed, and replicates the calculation when the next change is required[9]. This method is an advanced method of process in control industries in chemical plants and oil refineries .In recent years it has also been used in power systems harmonizing models .The main advantage of MPC is the authenticity that it allows the present time slot to be optimized,while keeping future time-horizon, but only implementing the existing time slot..MPC has the capability to predict prospect events and take control actions accordingly[10]. It is a digital control. 
The response of the corresponding MPC controller is shown below:-

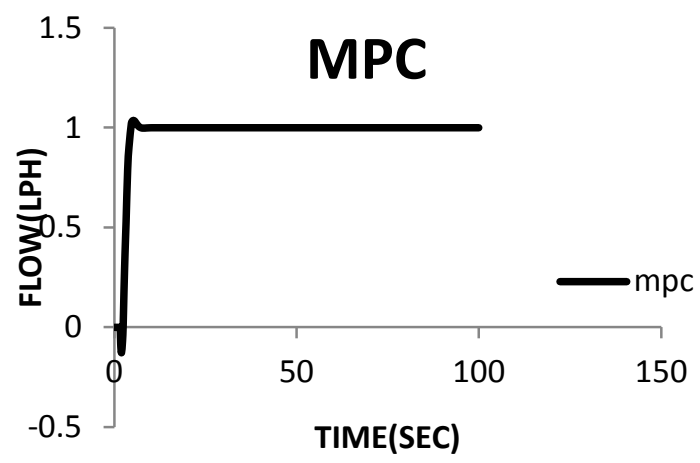

\section{RESULTS AND COMPARISON}

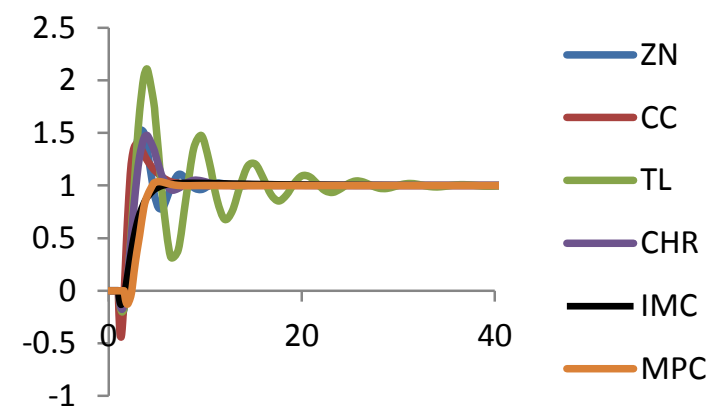

Thus the controllers like PID,IMC and MPC were compared and shown in a single graph. From this it is observed that MPC settles first compared to other two controllers.

\begin{tabular}{|l|l|l|l|l|}
\hline $\begin{array}{l}\text { Controller } \\
\text { Specification }\end{array}$ & $\begin{array}{l}\text { ZN- } \\
\text { PId }\end{array}$ & CC & $\begin{array}{l}\text { IMC- } \\
\text { PID }\end{array}$ & MPC \\
\hline Peak over & 0.9 & 0.5 & 0 & 0.2 \\
\hline shoot & 5 & 5 & 5 & 5 \\
\hline Rise time & 101.8 & 1.736 & 29.38 & $1.000 \mathrm{e}+004$ \\
\hline IAE & 35 & 15 & 8 & 5 \\
\hline ITAE & 555.2 & 1.664 & 562.9 & $1 \mathrm{e}+005$ \\
\hline ISE & 20.46 & 4.131 & 154.9 & $5 \mathrm{e}+004$ \\
\hline MSE & 2721 & 1.15 & 1023 & $5 \mathrm{e}+006$ \\
\hline
\end{tabular}

\section{CONCLUSION}

This paper shows the results obtained in the set of simulations for FODT processes when controlled with PID
controller,IMC and MPC controller. The scrutiny clearly explains that set-point in PID control is far from constrains whereas IMC control is better than PID. Compare to other two controls, MPC set-point is closer to constraint. In this paper it was proved that MPC tries to bring the process as close as possible to constraints without infringing them. Response for the entire six regions is compared with MPC ,PID and IMC. Here the time domain specifications such as rise time,settling time and overshoot and the performance indices such as IAE(Integral Absolute Error),ITAE(Integral Time Absolute Error),ISE(Integral Square Error) based on integral error for a step set point are considered for comparison as they are generally accepted as a good measure for system performance.

These simulation results are useful to do the required modifications in control system industry for optimal control.

\section{REFERENCES}

[1] Wayne Bequette: Process Control Modeling, Design, and Simulation PHI 2003.

[2] George Stephanopoulos: Chemical Process Control .An Introduction to theory and Practice PHI 2004

[3] Heikki N. Koivo and Anna Reijonen" Tuning of PID Controllers for Varying Time- Delay Systems," IEEE Trans. on, pp. 446-451, 2004.

[4] Ramon Vilanova," PID Controller Tuning Rules for Robust step response of First-Order-Plus-Dead-Time models," IEEE Trans. on, pp. 256-261, 2006.

[5] Process dynamics and control By Dale E Seborg, Mellichamp and Edgar.

[6] Rahul Shridhar , Douglas J.Cooper, "A Tuning Strategy for Unconstrained Multivariable MPC," Ind. Eng. Chern. Res, vol. 37, pp. 4003-4016, 1998.

[7] E. F. Camacho, Carlos Bordons, "Model Predictive Control," 2nd edition, Springer, 2004

[8] Skogested. S, "Simple analytic rules for model reduction and PID controller tuning", Journal Process Control, 2003.

[9] Sukanya R. Warier, Sivanandam Venkatesh , "Design of Controllers based on MPC for a Conical Tank System," IEEE-International Conference On Advances In Engineering, Science And Management , pp. 309-313, March 2012.

[10] V. R. Ravi, T. Thyagarajan, M. Monika Darshini, "A Multiple Model Adaptive Control Strategy for Model Predictive controller for Interacting Non Linear Systems" International Conference on Process Automation

[11] Mohammad Shahrokhi and Alireza Zomorrodi, "Comparison of PID Controller Tuning Methods" 